\title{
A Avaliação da Política Nacional de Saneamento Pós 64
}

\author{
Wilson Edson Jorge
} presente artigo foi desenvolvido a partir da Tese de Doutoramento apresentada na FAUUSP, em setembro de 1987: "A Polftica Nacional de Saneamento Pós-64".

O trabalho consistiu em uma avaliação sistemática e crftica da polftica de saneamento implantada em 1970, dando destaque às contradições que sobressalram do processo, a fim de ultrapassar o discurso sobre o Plano e recorrer a uma crftica global sobre o mesmo, para entender aquelas contradições e os limites que o Plano apresentou.

A polftica de saneamento urbano do Governo Federal só pode ser compreendida enquanto produto de vários interesses, dos quais os principais foram a polticica econômica mais ampla do Governo Federal, os interesses do BNH enquanto instituição financeira e os interesses do forte "lobby" público e privado que se cristalizou em torno daquela política. This paper is based on the Ph.D. thesis named 'A Polttica Nacional de Saneamento Pós64' (The National Policy on water supply and wastewater Disposal after 1964) submitted in September 1987 at FAUUSP.

The research consisted in a systematic evaluation upon the national policy of 1970, with special concern to the contradictions raised on the process of its implementation. Such an evaluation aimed at to overlap of the official discourse as a way to understand the refered contradictions and the limits of the policy itself.

The federal government policy on water supply and wastewater disposal may only be understood as the result of a combination of different interests, among which are particulary important the economic federal policy, the BNH - National thousing Bank concerns as a financial institution and the strong lobby composed by private and public actors organized around that policy.
Artigo elaborado com base na Tese de Doutorado "A polfica nacional de saneamento poss-64". apresentada em setembro de 1987. Orientador: Prol. Dr. Flávio Villaça. 


\section{A Estruturação do PLANASA}

A primeira indagação que ocorre na abordagem da poltica de saneamento urbano é o por quê da escolha desse setor, como elemento privilegiado de uma poltica especlfica do Governo Federal. Que vantagens o setor oferecia e, ao mesmo tempo, que problemas o Governo Federal resolveria com a montagem dessa politica?

Parte da resposta se prende à própria polftica habitacional desenvolvida pelo governo, já a partir de meados de 1964, através de um banco criado inicialmente para tal fim, o Banco Nacional de Habitação. Os objetivos pretendidos com a polftica habitacional, sua evolução e a própria evolução por que passou o Banco, bem como os resultados obtidos, já foram bastante estudados por diversos autores.

O motivo básico que levou o BNH a procurar outros mercados para seus empréstimos foi apresentado por Souza. De uma posição de recursos insuficientes para implementar seus programas, com a criação do FGTS e o estabelecimento da competência do BNH para geri-lo em 1967, o Banco passou para uma posiçāo de "excesso" de recursos, com a necessidade de aplicá-los, garantindo-lhes taxas minimas de capitalizaçāo. A partir dal o BNH ampliou e diversificou seus programas de aplicação dos fundos, enquanto que o mercado habitacional a quem se destinavam os recursos do FGTS - Fundo de Garantia por Tempo de Serviço, basicamente constituldo por população de baixa renda, apresentou estrangulamentos à absorção dos recursos disponiveis. $\mathrm{Na}$ condição e necessidade de encontrar aplicaçōes rentáveis para seus recursos, o BNH dirigiu-se para os estados e os municípios.

A argumentação de Souza foi retomada por Maricato que explicitou os reveses da polftica habitacional do perlodo.

Por outro lado, a ação do Banco, financiando conjuntos residenciais principalmente em grandes cidades, expôs as deficiências em infra-estrutura em geral e, especificamente, as deficiências dos próprios conjuntos. Esse processo familiarizou o Banco com a potencialidade que os serviços de infra-estrutura urbana ofereciam para investimentos.

O setor de saneamento oferecia grandes vantagens como mercado de investimentos para o $\mathrm{BNH}$. Em primeiro lugar, era e continua sendo um mercado muito amplo, com demandas reprimidas e o consumo de água (o subsetor mais vital do saneamento) é crescente, pois seu mercado consumidor corresponde a toda população urbana do pals. A situação de abastecimento de água, na década de 60 , continuava precária no pals, principalmente nas grandes cidades e a situação dos esgotos era ainda mais crftica.

As soluçōes para esses problemas exigiam grandes investimentos em obras para ampliação das redes e atendimento ao consumo. O pagamento dos serviços de saneamento, via tarifa, era um componente menor da despesa da população, o que dava certa garantia de que esse componente não sofreria estrangulamentos por falta de pagamento. Finalmente, o setor de saneamento sempre foi um setor de grande importância polftica, face à importância de tais serviços junto à população.

Qualquer obra ou melhoria no atendimento em saneamento, trazem imediatamente prestlgio à administração junto à população beneficiada, o que torna o setor muito importante para uma polftica de legitimação do poder.

Não se pode esquecer também que a ampliação das áreas de atuação do BNH significava ampliação do próprio poder do órgão e do setor polftico e burocrático dentro do qual o Banco se inseria. O poder tem sua própria dinâmica e, dentro da poltica geral de concentração do poder que o Estado vinha implantando, o Banco (isto é, toda estrutura de poder em que ele se vinculava) buscou novos espaços para atuar e, dentro 
das condiçōes concretas, procurou ampliar o setor de saneamento para sua área de influência.

Outra vantagem que o setor de saneamento oferece e que é importante para o subsetor da construção pesada, interessado em ampliar sua ação sobre o urbano, relaciona-se com a terra urbana. Na produção da habitação, o elemento terra urbana é fundamental, principalmente no processo de captação da mais valia, garantindo ao proprietário, parte substancial da mais valia gerada no processo. Essa dinâmica do processo de produção habitacional torna o processo mais complexo, ampliando os agentes em cena e reduzindo, em última análise, as taxas de lucro da indústria da construção civil. No caso de saneamento, a maior parte da terra urbana que participa do processo de implantação do sistema é de propriedade pública: são as ruas, as áreas marginais de cursos d'água. São poucas as quantidades de terra de propriedade privada necessárias a esses sistemas, correspondendo, eventualmente, às áreas para as estaçōes de tratamento de água e de esgotos (que podem ser instaladas relativamente afastadas das áreas ubanas, ou seja, em áreas de baixo valor) e para a posse das quais o Estado pode lançar mão do recurso da desapropriação, eliminando ou diminuindo as condições de barganha do proprietário.

Portanto, no setor de saneamiento, a reprodução do capital está vinculada diretamente ao setor produtivo, com reduzidos figurantes no processo de captação da mais valia.

A segunda indagação que ocorre face à montagem de polftica de saneamento é por que ela só ocorre, com vigor, a partir de 1971, com a implantação do PLANASA. Enquanto o setor habitacional foi objeto de destaque da polftica social e econômica do regime militar, já em 1964, por que somente após sete anos é que se efetivou uma polfica de vulto para o setor de saneamento?

O principal motivo porque isso ocorreu foi que a poltica habitacional sempre padeceu de fundos de investimentos a longo prazo e, até 1964, eles eram poucos e descapitalizados, já que os ativos e empréstimos dos fundos não eram corrigidos face à inflaçāo. É a partir de 1967, com o estabelecimento da competência do BNH para gerir o FGTS, que o Banco se vê com "excesso" de recursos, face à capacidade restrita do setor em que atuava, do mercado habitacional da população de baixa renda, em absorver recursos.

A montagem institucional para implantar a polftica do Governo Federal de Saneamento Urbano foi desencadeada sucessivamente: a criaçāo do FGTS, sua passagem para controle do $\mathrm{BNH}$, a formalização dos princípios a serem geridos pela politica federal de saneamento, a criação do Fundo de Financiamento para o Saneamento - FISANE (agosto de 1967) e a passagem de seu controle para o BNH, a criação do Conselho Nacional de Saneamento (setembro de 1967). A origem dos Fundos de Financiamento para Água e Esgotos - FAE passou pela polftica do $\mathrm{BNH}$, em estímulo à criação de fundos regionais para saneamento (agosto de 1968). Finalmente em 1969, ० BNH foi autorizado a aplicar os recursos do FGTS em sistemas de água e esgoto.

Portanto, já tendo como objetivo a entrada no setor de saneamento, o Governo Federal, através do $\mathrm{BNH}$, montou a estrutura institucional necessária para implantar sua polttica, em dois anos, de 1967 a 1969.

Outra dificuldade para o Governo Federal implantar sua polftica de saneamento urbano, foi a resistência dos municípios a cederem seus direitos de gestão dos sistemas de saneamento, incluindo nessa cessão o próprio acervo dos sistemas. Isso demandou uma ação polftica que teve de ser montada via Governos Estaduais, mais submissos e controlados politicamente pelo Governo Federal. Por outro lado, foi necessário haver um certo perlodo entre a reforma tributária implantada e o conseqüente e progressivo es- 
vaziamento financeiro dos municlpios, o que facilitou sua submissão à polticica de saneamento federal. Mesmo assim, muitos municlpios, e vários deles importantes demografica e economicamente, resistiram até o presente à pressão do Governo Federal e não se incorporaram ao PLANASA.

O fato da montagem da politica federal de saneamento ter sido desenvolvida através de um banco, significou que a tônica básica incorporada aos serviços de saneamento foi financeira. A perspectiva dos serviços serem de cunho social foi deixada de lado, ou melhor, apenas suscitada na defesa e apologia da polftica de saneamento. Na prática, - BNH passou a financiar, como entidade bancária, estados e municipios carentes de recursos e de vias alternativas para obtê-los. A obtenção dos recursos do Banco passou a ser obrigatoriamente vinculada, após o PLANASA, à criação do FAE e das Companhias Estaduais de Saneamento - CES, através dos quais os recursos eram repassados aos municlpios, via companhia local vinculada à FAE estadual. As imposiçōes do Banco explicitaram e delimitaram a tônica empresarial do modelo PLANASA.

O modelo estabelecido para o PLANASA, via BNH, foi altamente centralizador. Para facilidade e controle dos empréstimos, os mesmos eram negociados via CES, isto é, o SFS vinculava-se a 28 CES que geriam, cada uma, pelo sistema de caixa única, todos sistemas de saneamentos locais, dos municipios aderentes ao Plano. Os programas, investimentos, polticica tarifária dos 2.929 municipios brasileiros aderentes ao PLANASA, eram resolvidos via as 26 CES criadas, uma para cada estado. A lógica da centralização, para fortalecimento das CES e dos FAE exigiu que cada CES gerisse os sistemas de saneamento da maior parte dos municipios do seu estado. Essa lógica de subordinação dos municípios ficou evidente na Exposição de Motivos no 3 (abril de 1975) do Conselho de Desenvolvimento Social que propunha, como ideal, a integração de todos municípios brasileiros às CES. Essa centralização, beneficiada pela polttica centralizadora do Governo Federal, passou pela cooptação dos estados via CES e pela cooptação dos munićpios, via os próprios estados, que se encarregaram das pressōes poltiticas e financeiras sobre os mesmos. Na realidade o sistema de monopólio estatal dos serviços a nivel municipal, transmutou-se em um monopólio de serviços mais amplo, a nivel estadual, e em um monopólio financeiro absoluto, a nivel federal.

O sistema financeiro previsto pelo PLANASA viabilizava e dava plenas garantias aos empréstimos do $\mathrm{BNH}$, responsabilizando os Estados, via CES, pelos mesmos e exigindo que integrassem com até $5 \%$ de suas receitas, os FAE. Assim, cada empréstimo do $\mathrm{BNH}$ exigia uma igual contraparte do Estado, via $F A E$, o que multiplicava o alcance dos empréstimos do Banco. A criação do PLANASA repousou sobre um sistema financeiro que levou à centralização financeira e econômica do sistema de saneamento, às expensas dos estados, dos municípios e, finalmente, na base sustentatória da pirâmide, dos consumidores, dos quais a maior parte constituída por assalariados, dos quais a maior parte, de baixa renda.

Juntamente com a montagem da polttica federal de saneamento, da qual o PLANASA se constituiu a forma e expressão mais amadurecida e abrangente, cresceu o "lobby" de segmentos dos setores privado e público, com interesses vinculados àquela polftica.

$\mathrm{Na}$ avaliação da poltitica de saneamento, é fundamental a inserção desse "lobby" que atuou, basicamente, dando suporte a uma polftica enfaticamente de obras, em detrimento do funcionamento dos sistemas de saneamento.

No discurso montado pelo Estado para justificar o PLANASA, as crticas mais enfáticas formuladas à situação dos serviços de saneamento, no período anterior a 64 , recalram sobre os miunicipios. Essas crficas se referiam à incapacidade financeira administrativa e polticica dos municípios em equacionarem e resolverem adequadamente os problemas vinculados às demandas urbanas, em serviços de água e de esgotamento sanitário. 
Por um lado, essas criticas procediam, quando se referiam às condiçōes de funcionamento da entidade encarregada dos serviços, geralmente um órgão de linha, um departamento ou secretaria regidos pelo sistema de direito público, com pouca flexibilidade face às necessidades de ampliação e manutenção dos sistemas de saneamento. Porém essas condiçōes, dentro da linha de modernização e eficiência dos órgãos do Estado, que presidiu a polftica pós 64 , foram superadas pelo menos parcialmente, pela constituição, a nivel municipal, de empresas públicas regidas pelo sistema de direito privado. O mesmo princlpio de organizaçăo institucional que presidiu a montagem das CES, poderia ser utilizado a nivel municipal, superando, portanto, deficiências ditas inerentes da burocracia vinculada à administração direta.

Por outro lado, essas crticas foram desenvolvidas a partir de um diagnóstico parcial dos problemas de saneamento nos municípios, que não consideraram dois fatores essenciais para se compreender o contexto daqueles problemas: o crescimento acelerado das populações urbanas no Brasil, a partir da década de 50 , principalmente nas cidades maiores, e o progressivo esvaziamento tributário dos municípios, fator esse já ressaltado anteriormente.

\section{Conseqüências da Inserção do PLANASA na Politica mais ampla do Estado e do BNH e das Bases Estruturais em que o Plano foi desenvolvido}

A polftica de saneamento urbano do Governo Federal, só pode ser compreendida, enquanto vista como um produto de vários interesses coincidentes, superpostos e mesmo antagônicos, mas cujo vetor principal foi a polftica econômica mais ampla do Estado, seguido dos vetores relativos aos interesses do Banco, enquanto instituição financeira, e aos interesses do forte "lobby" público e privado que as cristalizou em torno daquela polttica. Nessa constelação de interesses e de pressōes, o usuário final, o consumidor, não teve nenhuma participação na formulação e implantação daquela polttica e sua influência somente ocorreu na medida em que começaram a surgir organizaçōes populares que passaram a exigir qualidades mínimas para os locais de moradia, inclusive de saneamento.

Enquanto instrumento de crescimento econômico a polftica de saneamento promoveu 0 crescimento do setor da construção civil e principalmente do subsetor da construção pesada. A predominância das grandes firmas construtoras, como força atuante do "lobby" de saneamento, fez com que a polftica de saneamento fosse encaminhada para dar ênfase a obras e para privilegiar grandes obras, cuja escala e complexidade se enquadrassem no perfil tecnológico e econômico daquelas firmas.

Os recursos aplicados pelo BNH no PLANASA aumentaram substancialmente de 1981 a 1983, em valor absoluto, de 48 milhōes de UPC em 1980 (US\$ 686 milhōes), para 94 milhōes de UPC (US\$1.344 milhōes) no ano seguinte, já em plena recessão. Porém, a partir de 1983, ano em que a recessão atingiu o seu auge (variação anual do PIB igual a $-3,2 \%$ ), a direção da polftica econômica do Governo Federal restringiu o repasse de créditos, a partir da Resolução 831 . Mesmo com todo "lobby" de saneamento pressionando o governo, as restrições somente foram levantadas um ano após seu início, quando o processo recessivo já estava diminuindo (em 1984 a variação do PIB subiu para $+4,5 \%$ ). Em suma, a polftica econômica do Governo Federal manipulou a polttica de saneamento em função dos objetivos mais amplos fixados e que são aparentemente contraditórios, se vistos exclusivamente do ângulo especffico da polttica de saneamento. O manifesto que a Associação Brasileira de Engenharia Sanitária e Ambiental ABES apresentou ao pals, como denúncia de uma política contraditória e prejudicial, é o exemplo da avaliação que o "lobby" pretendeu passar para a opiniāo pública, não 
porque desconhecesse as razōes que levaram o centro de poder da burocracia estatal à restrição dos créditos, mas simplesmente porque estavam com seus interesses ameaçados com aquela polttica.

$O$ indício e exemplo mais evidente do controle que o centro de poder do Estado encarregado da polftica do pals, manteve sobre a polftica de saneamento, foi o controle dos aumentos tarifários. A Lei 6.528 , de $05 / 78$, que normatizou a política tarifária em saneamento, vinculou a aprovação dos reajustes tarifários propostos ao Conselho Interministerial de Preços, sob o controle dos Ministérios do Planejamento e da Fazenda.

O processo de concentração na SEPLAN das decisões econômicas, levou não só o $\mathrm{BNH}$ (inclusive o MINTER) a ficar estreitamente vinculado a sua órbita, como também explica o esvaziamento de órgãos como o Conselho Nacional de Polltica Urbana (CNPU), a quem estava vinculada a implantação de diretrizes de uma polttica de maior alcance "social" já estabelecida no II PND.

A vinculação polftica de saneamento a segmentos importantes da economia, principalmente o subsetor da construção pesada, levou aquela polftica a privilegiar as obras como seu elemento mais significativo e importante. Em palestra de 1983, na SABESP, o Engenheiro José Fernandes afirmou que a preocupação básica das empresas de saneamento foi a "realização de obras para que se pudesse dar água a quem não tinha, gerando concentração de esforços numa atividade em detrimento da atividade fim que é a operaçāo dos sistemas". Ou como expressa o editorial da revista Engenharia Sanitária, "como todos os esforços se voltaram para a construção dos sistemas, sentia-se, naturalmente, grande atividade no desenvolvimento de projetos e obras, enquanto a operação era implementada com menor ênfase".

Essa ênfase em obras desdobrou-se na ênfase em grandes obras, o que exigiu a concentração dos investimentos e a seleção, nas prioridades do plano, de obras que garantissem, além de grandes investimentos, um perlodo de implantação amplo, permitindo também uma maior estabilidade para as receitas das empresas construtoras.

O exemplo mais evidente dessa polftica foi o projeto SANEGRAN, relativo à captação e tratamento dos esgotos da região metropolitana de São Paulo. Esse projeto que gerou polêmicas exacerbadas sobre sua concepção e a forma de implantação, foi o exemplo mais agudo de concentração de investimentos em toda trajetória do PLANASA.

Inicialmente, as previsōes de investimento para todo o projeto chegavam ao total de 355 milhōes de UPC (US\$ 5.076 milhōes), equivalendo a uma média de investimento anual de 15 milhōes de UPC (US\$215 milhōes) durante 24 anos, no perlodo de 1977-2000.

Os investimentos nas obras do SANEGRAN foram de tal forma privilegiados na poltitica de saneamento e especialmente na polftica do SFS, relativa a esgotos sanitários, que o Estado de São Paulo, por conta basicamente do SANEGRAN, recebeu $63,7 \%$ de todos investimentos realizados pelo PLANASA em todo Brasil, até o ano de 1984. Além disso, toda a previsăo inicial de custos do projeto mostrou-se subdimensionada e, durante a implantação das obras, os investimentos per capita implicita nos Estudos de Viabilidade Global (EVG) da SABESP para o SANEGRAN, foram subindo: no EVG de 1977 o investimento per capita foi de 21,4 UPC (US\$ 306); no EVG de 1983 o investimento per capita já havia chegado a 48,6 UPC (US\$ 695).

Para a empresa construtora, esses aumentos significam, basicamente, aumento do próprio faturamento; sua lógica é a de faturar o máximo possível. A construtora não está preocupada, nào é de sua lógica preocupar-se com as repercussōes dos custos sobre as futuras tarifas, nem sequer com a viabilidade do empreendimento em causa. Seu objetivo é instalar-se na obra e garantir que o fluxo dos recursos do Estado continuem 
alimentando a operação. Quanto à forma de privilegiar as grandes empreiteiras nas obras, a avaliação do Sindicato de Engenheiros no Estado de Minas Gerais, criticando a ação da COPASA, aponta: "Nota-se cada vez mais a participação de um número reduzido de firmas empreiteiras de obras nas licitaçōes da empresa, em decorrência das exigências contidas nos editais que, por serem restritos, privilegiam principalmente aquelas de maior porte. Por outro lado, freqüentemente, essas obras têm sido subempreitadas para firmas menores, o que demonstra a incorreção da polftica de obras da empresa"

Nessas condições de direcionamento do mercado constituldo pelo Estado, para um setor fortemente oligopolizado, é comum a prática de acordo entre as grandes empreiteiras, pré-fixando a parte que cada uma levará das obras em concorrência.

Outro exemplo importante da concentração necessária dos investimentos, para privilegiar grandes obras, está nos investimentos realizados pelo Programa de Financiamento para Sistemas de Drenagem - FIDREN, vinculados à drenagem urbana. Também nesse caso, o Estado de São Paulo ficou com a maior parte, com $77.4 \%$ do total dos investimentos realizados no setor, para todo o Brasil, no perfodo 1973-1984.

Para justificaçāo dos investimentos em obras, a argumentação usada foi a de que os déficits em relação aos sistemas de saneamento urbano até 1970, eram tão pronunciados que a prioridade básica estava na ampliaçāo das redes e equipamentos dos sistemas de saneamento.

Essa justificativa é defensável, porém, insuficiente. A ênfase dada às obras nāo foi acompanhada de uma preocupação e medidas equivalentes, face à programação $e$ aos custos dos sistemas, à polttica tarifária, à operaçāo dos sistemas, o que levou a um aumento desproporcional e desnecessário dos custos dos sistemas implantados.

O exemplo da poltica tarifária formulada para o setor de saneamento é expressivo, face à ênfase dada às obras. Nesse sentido, vários trabalhos apareceram criticando aquela polftica e sua insuficiência, face às necessidades de viabilizar as CES dentro das regras do jogo, estabelecidas pelo PLANASA. O estudo mais amplo que aborda criticamente a poltica tarifária, observa a maneira simplista com que se colocou inicialmente, o tema da viabilidade global das CES, onde praticamente nenhuma atenção foi dedicada ao problema tarifário, como forma realista de se obter o equillbrio econômico financeiro das companhias. Conforme Fontenelle: "Na época, todas as prioridades do setor (grifo nosso) estavam voltadas para a execução de obras; em primeiro lugar, porque existia um grande déficit no abastecimento de água, de uma forma geral, e, em segundo lugar, porque não havia praticamente restrição de recursos (grifo nosso) o que, certo ou errado, fez com que se negligenciasse quanto à priorização dos investimentos, através de critérios que conduzissem ao equil!brio econômico-financeiro das empresas, por meio da minimização de suas necessidades tarifárias.

Só em 1978 o problema tarifário e a viabilidade econômico-financeira das CES foram objeto de legislação especffica onde a sistemática adotada substituiu "uma visão eminentemente financeira do problema tarifário das companhias, por uma visão econômica em que considera a depreciação e a remuneração do investimento no custo do serviço, onde anteriormente só eram incluídos os juros e amortizações dos empréstimos".

Os autores afirmam, portanto, que a prioridade do PLANASA foi a execuçāo das obras e essa prioridade, vinculada à abundância de recursos (o que resolvia a questão básica do BNH, logo após 1967, de onde investir os recursos dispon(veis do FGTS), fez que se negligenciasse a polttica tarifária, equacionando-a de forma insuficiente e restrita.

O estrangulamento tarifário, porém, só ocorreu com a evolução de toda polttica do PLANASA, quando as condiçōes externas se alteraram e os recursos para investimentos se reduziram. Enquanto o Plano atendeu os seus objetivos básicos, no sentido de 
serem os mais determinantes da polftica de regulação da própria economia do pals, de reprodução do capital via indústria da construção civil, drenando recursos compulsoriamente da população na forma de impostos e tributos, não se deu maior ênfase aos aspectos tributários, custos dos projetos, etc. Se por hipótese, as disponibilidades de recursos continuassem amplas e os estados apresentassem condiçōes financeiras de amortizarem os empréstimos, a polf́tica tarifária apesar de "negligenciada", de insuficiente para garantir a viabilidade das CES, provavelmente seria mantida.

Da mesma maneira, a dinâmica de expansão da poltica de saneamento, tendo como vetor básico a ênfase em obras, secundarizou, durante um largo perlodo, outros elementos da produçāo e gestão dos sistemas de saneamento, como a tarifa, os custos das obras, a viabilidade econômica dos projetos, etc.

Duas características básicas do Plano merecem destaque, pelas suas conseqüências. A primeira é relativa à natureza do órgão básico do sistema, o $B N H$, e se refere à lógica financeira da instituição e à estrutura do próprio PLANASA. A segunda característica, a centralização, correspondeu a uma conseqüência imediata e indispensável à gestão e expansão do Plano.

A lógica financeira do Banco, isto é, a necessidade de remunerar os recursos sob sua gestão e a polftica de juros diferenciados, estabelecida para os diversos estados, geraram um processo de seleção de áreas e de priorização de investimentos que tiveram, como conseqüência, privilegiar os investimentos nos estados em melhores condiçōes econômicas e financeiras que, por essas condiçōes, podiam absorver maiores investimentos e pagar juros maiores. Dessa forma, a lógica da concentração decorreu também da lógica financeira da instituição com o controle sobre os fundos do Plano. O Estado de São Paulo, mesmo pagando os juros mais caros do SFS (10,5\% ao ano), absorveu $42,6 \%$ do total de investimentos realizados pelo PLANASA, no Brasil, de 1968 a 1984 , seguido por Minas Gerais com $10,0 \%$ do total dos investimentos. Portanto, somente dois estados absorveram mais da metade dos investimentos vinculados ao Plano.

Com a redução dos recursos disponiveis para investimentos, na medida em que a situação financeira do BNH piorou e as condições de endividamento dos estados impediram maiores aportes aos $F A E$, as empresas de saneamento passaram a depender cada vez mais das receitas tributárias para suas necessidades face aos compromissos financeiros, investimentos e manutenção e operação dos sistemas de saneamento. Nessas condiçōes, as CES tenderam a priorizar o atendimento de áreas urbanas com maiores potenciais de receita, o que significou atender às zonas urbanas mais centrais da aglomeraçăo, com maiores densidades de ocupação e ou zonas ocupadas por populaçăo com maiores rendas, comparadas com as camadas da populaçăo de outras zonas carentes dos serviços de saneamento.

Da mesma forma, a tendência das CES foi de atender prioritariamente aos municípios maiores, em detrimento dos menores, com menos condiçōes de atender as exigências de viabilidade das CES. Esse parece ser um dos motivos por ainda haver uma quantidade muito grande de municipios de pequeno porte fora do PLANASA. Enquanto que, para os municípios maiores e melhor situados economicamente, houve interesse em permanecerem fora do PLANASA, resistindo muito para manterem sua autonomia no setor, para os municípios menores não parece haver esse interesse ou vantagens evidentes em ficarem fora do PLANASA. Aliás, o argumento mais usado pelo governo para justificar a caixa única das CES em cada estado foi que, a partir dela, seria possível atender os munićpios menores, normalmente "inviáveis" em relação aos sistemas de saneamento. Dos 1.170 municípios não atendidos pelas CES, 1.020 , isto é, $87,2 \%$ do total têm menos de 20.000 habitantes. É provável que na situação atual, as CES não 
venham facilitando a incorporação dos sistemas desses municipios o que poderia, pela própria argumentação vinculada às justificativas do PLANASA, colocar aquelas companhias em situação financeira mais diffcil do que apresentam hoje.

Quanto à centralizaçāo do sistema, a necessidade do PLANASA expandir o universo subordinado à polticica de saneamento, levou a um rápido e intimidante processo de incorporaçāo dos municipios às CES, exercido a partir de pressōes polfticas e financeiras. No relatório preliminar sobre o PLANASA, da Comissão de Saneamento, está expllcita a pressão exercida sobre os municlpios: "Os municlpios, tradicionalmente gestores dos serviços de água e esgoto, a partir de 1971, foram obrigados a optar entre aderir ao PLANASA, gerenciado pelo BNH e executado por CES, ou buscar obtenção de recursos através de outras fontes que não o $\mathrm{BNH}$, só que com extremas dificuldades para consegui-los".

As pressões dos governos estadual e federal sobre os municipios se deram basicamente através do bloqueio de financiamento oficial às obras de desenvolvimento urbano.

Diante dos problemas de saneamento e do potencial de receitas das comunidades médias e grandes, é provável mesmo que as CES tendam a colocar, em um segundo plano de prioridade, as pequenas comunidades. Por outro lado, no caso de haver divergências polf́ticas entre o munićpio e o estado, se este estiver controlando os serviços de saneamento, pode usá-los como instrumento de pressão sobre o município.

Em um aspecto, porém, a polftica do PLANASA coincidiu com a polftica de saneamento habitual dos municlpios: a ênfase com que se privilegiou os sistemas de abastecimento de água, em detrimento dos sistemas de esgotamento sanitário. Ao nivel de investimento realizado durante toda implantação do PLANASA, a avaliação do Conselho de Desenvolvimento em 1975 considerou o desempenho da polftica de saneamento insatisfatório no que se referiu aos serviços de esgoto.

De 1968 a 1984, os investimentos em água ficaram com 72\% dos investimentos globais do PLANASA e, se fossem considerados em separado os investimentos do Projeto SANEGRAN, que é um caso singular do setor de esgotos, aquele percentual seria ainda muito maior. De onde vem, quais são os motivos para essa preferência pelo sistema de abastecimento de água, em detrimento do sistema de esgotos e que extrapola mesmo o âmbito do PLANASA, para se estender como polftica de todo órgão público de saneamento?

Em primeiro lugar, evidentemente, porque o abastecimento de água é mais vital para a populaçāo. Ela pode sobreviver sem esgotos, mas nāo sem água. À medida que a urbanizaçāo avança, mais diff́cil se torna, para a populaçāo, se abastecer de água com meios próprios, ou porque os recursos naturais (lençol freático, cursos d'água, fontes) se tornam poluídos ou porque se esgotam. A necessidade de água fica evidente quando se verifica a posiçāo desse serviço face aos esgotos, nas reivindicaçōes que as populaçōes fazem junto aos órgãos públicos: a água vem sempre antes do esgoto quando, evidentemente, esses dois serviços ainda não existem.

Em segundo lugar porque, normalmente, os custos de sistemas de abastecimento de água são menos onerosos que os custos de sistemas de esgotamento sanitário. Em trabalho avaliando o PLANASA por Monteiro, tais custos foram calculados em 7 UPC (US\$100) per capita para o abastecimento de água e 14 UPC (US\$200) para os sistemas de esgotamento sanitário. Se com o mesmo investimento é possivel atender dois habitantes com água ou apenas um com esgoto, sendo a água mais essencial e mais requerida pela população, a tendência da administração pública é expandir os siste- 
mas de abastecimento de água em detrimento dos sistemas de esgotos sanitários, como vem ocorrendo nos municípios autônomos ou vinculados ao PLANASA.

O problema decorrente dessa postura é que, com o aumento de consumo de água (a população quando é servida por rede domiciliar, pelo conforto proporcionado, usa mais água do que anteriormente, quando resolvia individualmente seu abastecimento), aumenta a produção de esyotos domésticos que é a forma pela qual a água que entrou no domicllio acaba saindo. O paradoxo da situação portanto é que, quando a água é levada à população, se o seu esgotamento por rede pública não é resolvido, dentro em breve as condiçōes de saneamento ambiental que, num primeiro momento melhoraram, irão piorar.

As melhorias realizadas quanto aos sistemas de esgotos urbanos no pals foram minimas, face aos déficits do setor. Em 1983, apenas 32,4\% da população urbana do Brasil era atendida por rede de esyoto, o que não significa porém que esse esgoto recolhido fosse tratado. Pois a tendência dos governos estaduais, face à situaçāo crftica do setor e, em final de mandato no ano de 1986, foi investir apenas nas redes coletoras de esgoto e não no seu tratamento, transferindo para os cursos d'água, a poluição recolhida na cidade. Dessa forma, é o sistema hídrico que passa a suportar o ônus da poluição. Em 1986, dos $46 \%$ dos esgotos coletados na região metropolitana de Săo Paulo, apenas $5 \%$ eram tratados.

\section{As Contradições da Política do Governo Federal no Processo que presidiu a Implantaçāo e o Desenvolvimento do PLANASA}

A primeira contradição se estabeleceu entre, de um lado, a polftica da tarifação realista para o PLANASA, isto é, a fixação de tarifas para os serviços de saneamento capazes de suprir todos os custos vinculados à implantação e gestão dos serviços pelas FAE e, de outro lado, a polftica econômica do Governo Federal implicando no rebaixamento de salários, isto é, uma maior exploração do trabalho. Essa exploração foi direta, congelando salários por decreto ou alterando os índices oficiais que mediam as variações da inflação, de forma que os aumentos salariais, a partir desses Indices, eram feitos abaixo das taxas reais de inflação, perdendo parte de seu valor real. A exploração foi indireta, eliminando-se os subsídios de serviços básicos à população, que passaram a ter de ser pagos integralmente.

À medida que o governo, de um lado, reduziu os salários através de índices artificiais, de outro foi obrigado a reduzir também os valores reais das tarifas de serviços públicos, pois os aumentos tarifários face ao sistema de controle de preços do governo estavam vinculados aos mesmos indices de correção dos salários. Essa contradição não tem sido explicitada em vários trabalhos que criticam a polftica tarifária para o setor de saneamento apenas em relação às necessidades econômico-financeiras do setor e sua conclusão termina por se restringir a que o setor de saneamento merecia um tratamento justo e não irreal quanto as suas tarifas. $O$ problema é que o sistema tarifário, não só do setor de saneamento, como de outros setores de infra-estrutura, como o setor energético ou de transporte, passou a fazer parte inseparável da polf́tica econômica do Estado, não uma parte destacável do todo, mas um elemento intrinsecamente vinculado e necessário àquela polftica. Negar a polftica tarifária de serviços públicos, seria negar a espoliação montada sobre o trabalhador, que é um dos sustentáculos básicos da polttica econômica do governo brasileiro.

O achatamento tarifário, resultado contraditório da polftica econômica do Estado é um dos impasses a que chegou o modelo do PLANASA, como explicita o trecho seguinte de revista Engenharia Sanitária: 
"O achatamento tarifário ocorrido no setor, conduziu à descapitalização dos órgãos de saneamento, tornando imprescindivel a progressiva recomposiçăo das tarifas de água e esgotos. Os dados que se seguem ilustram o referido achatamento, permitindo comparar a evolução de preços de diferentes setores, no perlodo 1977-1984:

$\begin{array}{lr}\text { Energia elétrica } & 167 \text { vezes } \\ \text { Gasolina } & 160 \text { vezes } \\ \text { Indice Geral de Preços - IGP } & 143 \text { vezes } \\ \text { Índice de Produtos Industriais por Atacado } & 142 \text { vezes } \\ \text { Salário Mínimo } & 119 \text { vezes } \\ \text { Água e Esgotos } & 77 \text { vezes" }\end{array}$

A espoliação do trabalho acentuada pelo regime militar levou a uma segunda contradiçāo na polftica de saneamento: à incapacidade gradativa da populaçăo, nos seus extratos baixos de renda (a maior parte dos consumidores urbanos de água), de pagarem as contas dos serviços, isto é, de propiciar às CES, os recursos tarifários cada vez mais importantes para as companhias, face à escassez de outras fontes de recursos. Que essa situaçăo se tornou crfica para a politica de saneamento, já expressava o presente das ABES: "O presidente da ABES, Walter Pinto Costa, acredita que o problema se situa na esfera salarial. Enquanto as tarifas sāo corrigidas por Indices atrelados à inflação, os salários estão contidos pelo Decreto 2.065. E é da massa de salários que vem a cobertura das tarifas"

A terceira contradiçăo entre a polttica econômica do Governo Federal e a polltica montada para o PLANASA, ocorreu no progressivo esvaziamento financeiro e polftico dos estados e municípios, provocado pelo Governo Federal e que ocasionou, por outro lado, a incapacidade financeira dos estados de captarem novos empréstimos para investimentos, inclusive no setor de saneamento e de canalizarem novos recursos aos $F A E_{\text {, }}$ que foram sendo progressivamente descapitalizados. Na medida em que a pretendida autonomia das CES repousava na capitalização progressiva dos $F A E$, via taxas de retorno, prescindindo de novos aportes do Estado, a polftica econômica e do Governo Federal achatando as tarifas, comprimindo salários e reduzindo a capacidade financeira dos estados, impediu aquela capitalização, levando a polftica de saneamento a um impasse.

Finalmente, o estabelecimento da fonte de recursos básicos do BNH para a polftica de saneamento básico, no FGTS, fez com que essa polftica passasse a depender do comportamento do próprio Fundo. E como já foi visto, o FGTS teve seus saldos bastante diminuldos nos perlodos recessivos da economia, restringindo as disponibilidades do $\mathrm{BNH}$ para novos investimentos, e é justamente nos perfodos recessivos que o Estado vem utilizando sua polftica habitacional e de saneamento, como instrumento de atenuaçăo da crise. Nesses perlodos em que seriam necessários maiores recursos para o setor, os recursos desceram a niveis muito baixos, restringindo o alcance da polftica pretendida.

O "lobby" das grandes empresas construtoras se constituiu, em determinado momento, em uma oposição à polftica econômica do estado, Estado esse que garantiu a formaçāo e desenvolvimento do próprio "lobby" Na medida em que a ação do Estado se dirigiu para enfrentar a crise do sistema econômico, tomando medidas que prejudicaram os investimentos no setor de saneamento, o "lobby" se voltou contra essas medidas procurando, inclusive, o apoio da opinião pública. Esse "lobby" está hoje na berlinda como um dos principais componentes do processo de corrupçăo e de venda de influências dentro do governo, obieto de investigação por uma Comissāo Parlamentar de Inquérito, do Congresso Nacional. 


\section{Os Resultados do PLANASA}

A incapacidade demonstrada pelo governo para resolver os problemas financeiros do $\mathrm{BNH}$, vinculados à própria estrutura montada para a circulação dos recursos geridos pelo Banco, levou ao seu fechamento. Segundo Luiz Carlos Mendonça de Barros, diretor da área de mercado de capitais do Banco Central, em 1986, "as enormes falhas estruturais e os subsidios do passado a empresas construtoras e a compradores da casa própria, em ambiente de inflação elevada, jogam a estimativa do rombo do Sistema Financeiro da Habitação para meio trilhão de cruzados".

Porém, se olhado do ponto de vista estrito das funçōes que o BNH exerceu para o sistema econômico, o banco cumpriu e muito bem, seus objetivos. Foi um instrumento útil no processo de acumulação de capital, promoveu o crescimento da economia, "capitalizou as empresas construtoras e os agentes financeiros e dinamizou todo o setor privado de promoção imobiliária" além de favorecer a expansão do setor oligopolizado das empresas nacionais da construção pesada.

O déficit ou rombo que o banco apresentou ao ser fechado foi repassado em parte aos usuários do sistema, como pretendia o então diretor da dívida pública do Banco Central, André Lara Rezende, e parte acabará sendo incorporado ao déficit do Tesouro Nacional, uma forma de socializar o déficit da instituição.

Do ponto de vista financeiro, a situação das CES veio a se tornar crftica, estando essas companhias no limite de endividamento possivel e numa perspectiva de acentuação dos seus déficits.

Com o fechamento do $\mathrm{BNH}$, deixou de haver uma polftica centralizada de estabelecimento de tarifas para as CES, deixando a cada uma, a decisão de fixação das tarifas. Nesse novo processo, a poltica das CES passou a ser a mais simplista, elevando bastante suas tarifas, acima da inflação, polftica essa adotada pelo atual Governo Federal para todas tarifas de serviços públicos, dentro da polftica mais ampla adotada para a redução do seu déficit. Como resultado dessa polftica de aumento tarifário, não seguida de alteraçōes mais estruturais da polftica de saneamento, a população está pagando valores muito altos para os serviços de água e esgotos. A Sabesp cobra atualmente cerca de US $\$ 0,60$ por $\mathrm{m}^{3}$ de água, um Indice muito superior à média cobrada anteriormente.

Em relação ao atendimento à população, o PLANASA melhorou sensivelmente as condições urbanas de abastecimento de água de um modo geral, chegando à década de 80 , atendendo $80 \%$ da população urbana do Brasil. Observa-se que esse percentual tende a cair nas condiçōes atuais e que o atendimento apresenta desniveis regionais acentuados, com determinados estados situados bem abaixo da média brasileira. Quanto às condiçōes de esgotamento sanitário urbano, a situação atual permanece crltica, com apenas $32,4 \%$ da população urbana brasileira atendida e, muito provavelmente, apenas parte do esgoto coletado está sendo tratado, o que significa um aumento da carga poluidora despejada nos corpos d'água receptores. Essa situação ainda é mais grave se a avaliação for regional, pois alguns estados têm apenas $1 \%$ da população urbana atendida por rede geral de esgoto.

Mesmo com todo aparato de pressão exercido sobre os estados e municípios, o PLANASA não conseguiu trazer para o seu controle 1.170 municípios $(28,5 \%$ do total de municípios brasileiros) que, mesmo com todas dificuldades vinculadas a essa decisão, mantiveram sua autonomia nos serviços de saneamento urbano. Essa resistência espeIha bem as desvantagens que o PLANASA trazia para as condições polfticas, administrativas e financeiras locais. 
O PLANASA gerou um processo de aumento dos custos gerais per capita dos sistemas de saneamento, muito superior às previsōes inicialmente formuladas nos estudos de viabilidade e nos projetos desenvolvidos durante o Plano. Os investimentos per capita previstos pela Secretaria dos Serviços e Obras Públicas do Estado de São Paulo (Adesão ao PLANASA, 1973) foram de 6,7 UPC/hab. (US\$ 96/hab.) para os sistemas de abastecimento de água e 9,3 UPC/hab. (US\$133/hab.) para os sistemas de esgotamento sanitários. Os valores reais desses investimentos (médias da SABESP, 1973-1984) chegaram, em 1984, a 20,0 UPC/hab. (US\$286/hab.) para os sistemas de água e 24,4 UPC/hab. (US\$ 349/hab.) para os sistemas de esgotos. Os investimentos per capita do projeto SANEGRAN foram subindo progressivamente, à medida em que foram sendo implantados e revistos seus Estudos de Viabilidade Global, pela SABESP. Assim esses estudos chegaram aos valores de 21,4 UPC/hab. (US $\$ 306 / \mathrm{hab}$.) em 1977 e 48,6 UPC/hab. (US\$ 695/hab.) em 1983.

Muitas são as causas apontadas para explicar esses aumentos de custos que ocorreram, de um modo geral, em todo pals: concepção de projetos com previsão de atendimento de muito longo perlodo, criando ociosidade em unidades de custo elevado, e exigindo investimentos desnecessários; gestāo incompetente por parte das CES; utilização de tecnologia mais sofisticada do que seria necessário, sem busca de soluçōes mais simples, adaptadas às condiçōes locais do projeto; orientação das obras para grandes empreiteiras. Essas causas estão, em última análise, vinculadas aos objetivos principais da polticica de saneamento: expandir o poder e a ação centralizadora do Estado sobre a sociedade e promover a reprodução do capital em condiçōes vantajosas através de uma polftica de aumento da exploração sobre o trabalho.

A ênfase nas obras levou, inclusive, à montagem de um sistema de controle operacional deficiente, nas CES. Na cidade de São Paulo, as perdas no sistema de abastecimento de água chegaram em 1977, a 35,63\% do volume de água produzido. Um programa de controle operacional da SABESP conseguiu reduzir esse volume de perdas a $27,07 \%$ em cinco anos.

Ao nivel da polftica tarifária, a adoção de tarifas diferenciadas por classe de consumidor (definida pelo volume do consumo e pela atividade exercida) significou um repasse de custos entre as camadas sociais, mas com rígidos limites como polftica redistributiva.

Esses limites foram delimitados por um lado, pela poltica do "realismo tarifário" que manteve as receitas tarifárias como a mais importante fonte de receita das CES, impedindo o seu rebaixamento; por outro lado, pela estrutura de renda muito concentrada da população, impedindo que a redistribuição interna dos custos dos sistemas, via tarifas, atingisse niveis significativos.

\section{Conclusões}

O PLANASA melhorou as condiçōes urbanas de abastecimento de água, chegando o pals, à década de 80 , com um atendimento de $80 \%$ de sua população urbana. Essa situação permaneceu praticamente a mesma, na década seguinte.

O Estado não teve, de fato, uma polltica social vinculada à sua polltica de saneamento urbano. A funcionalidade da polftica de saneamento consistiu em uma politica empresarial sem qualquer tipo de subsidio que comprometesse o retorno, via tarifas, dos empréstimos do $\mathrm{BNH}$. A polfica de saneamento deu preferência às obras e às grandes obras, atendendo ao "lobby" das grandes empreiteiras. Uma das conseqüências mais sérias dessa polftica foi sua contribuiçāo para o aumento dos custos gerais das obras. A formação de todo um setor da construção pesada, que é o mesmo que faz as gran- 
des obras públicas, como hidrelétricas, metrôs, auto-estradas, é ilustrativo das relaçōes entre o regime autoritário e setores empresariais que cresceram com o autoritarismo. Aqui, no reino da "Lei de Gerson", mostra-se a face mais escandalosa do autoritarismo brasileiro, a construção do Estado do Mal-Estar. É esse tipo de contradição, de que está recheado o sistema brasileiro, que a democratização é chamada a dar conta.

A estrutura montada para o SFS foi uma decorrência da polltica adotada no perlodo do regime militar de centralização do poder à custa da autonomia dos governos estaduais e municipais. A centralização do SFS subordinou, através de um processo articulado de pressōes, os municípios e os estados ao PLANASA. Mesmo com todo aparato de pressão exercido sobre os municlpios, o PLANASA năo conseguiu trazer para o seu controle 1.170 municipios (29\% dos municlpios do pals), muitos deles municipios grandes e importantes que mantiveram sua autonomia nos serviços de saneamento urbano, apesar das dificuldades vinculadas a essa decisāo.

Quando da extinção do $\mathrm{BNH}$, a situação das CES já era crftica, a maior parte delas com um déficit progressivo e incapazes de resolver seus problemas econômicos e financeiros via tarifas. O déficit das CES passou a ser bancado pelos respectivos estados, acumulando maiores déficits e procurando repassá-los ao Governo Federal. Essa foi a última contradição de um sistema que tinha como modelo, uma polftica empresarial para o saneamento.

A extinção do BNH não trouxe qualquer conseqüência estrutural ao SFS, além de permitir às CES maior autonomia no estabelecimento de tarifas que levou a um aumento explosivo das mesmas. Os problemas estruturais da poltica de saneamento montada via PLANASA permanecem, o que é mais uma herança da Nova República onde se mudou para que as coisas permanecessem as mesmas. É preciso de novas luzes para se conhecer a verdadeira história da não-saneada relaçāo entre grupos econômicos e um Estado de exceção.

\section{Referências Bibliográficas}

COUTINHO, Luciano G. Estrutura e Gênese da Administração Pública de São Paulo. Administração Centralizada do Setor Público Estadual: Saneamento Básico. FINEP-FUNDAP, São Paulo, 1978.

FAGNANI, Eduardo. O perfil da Intervenção Governamental no Saneamento Básico: Principais Dilemas em São Paulo. FUNDAP, São Paulo, 1984.

FONTENELLE, José Amaury Teles, et al. A Viabilidade Económica dos Projetos e da Companhia Estadual de Saneamento, no Modelo do Planasa - Uma Análise Crfica. Sabesp, São Paulo, 1983.

JORGE, Wilson Edson. Planasa - A Polftica Nacional de Saneamento Pós-64. São Paulo, 1987. Tese (dout.) - FAUUSP.

MARICATO, Erminia. Indústria da Construção e Polfica Habitacional. São Paulo, 1983. Tese (dout.) FAUUSP.

MONTEIRO, Josế Roberto de A. P. do Rego. A Posição do Brasil Face à Década de Água. In: Engenharia Sanitária, Rio de Janeiro, v. 20, n. 4, 1981, p. 40.

Planasa - Avaliaçăo e Perspectivas. In: Engenharia Sanitária, Săo Paulo, 1985, p. 392.

Planasa considera prioritário o Programa de Controle Operacional. In: Engenharia Sanitária, Rio de Janeiro, n. 1, jan./mar. 1985, p. 22.

Programa Estratégico de Desenvolvimento - 1978-1970, jul. de 1967.

REINACK, Klauss. Obras de Saneamento e Controle da Poluição das Aguas da RMSP - Plano Diretor Sanegran. In: Separata de Revista DAE, São Paulo, ns. 110 e 111, 1977.

Sindicatos de Engenheiros no Estado de Minas Gerais, 1983, p. 9.

SOUZA, Berenice G. V. de. O BNH e a Polnica do Governo. Belo Horizonte, 1974. Diss. (mestr.) $F F C H$, UFMG. 